\title{
Beyond Population: Everyone Counts in Development
}

\section{Joel E. Cohen}

\begin{abstract}
This essay reviews important demographic trends expected to occur between 2010 and 2050, indicates some of their implications for economic and global development, and suggests some possible policies to respond these trends and implications. The century from 1950 to 2050 will have witnessed the highest global population growth rate ever, the largest voluntary fall in the global population growth rate ever, and the most enormous demographic shift ever between the more developed and less developed regions. In the coming half century, according to most demographers, the world's population will grow older, larger (albeit more slowly), and more urban than in the 20th century, but with much variance within and across regions. No one knows what population and demographic characteristics of humans are sustainable, but it is clear that having a billion or people chronically hungry today results from collective human choices, not biophysical necessities. Concrete policy options to respond to demographic trends include providing universal primary and secondary education, eliminating unmet needs for contraception and reproductive health, and implementing demographically sensitive urban planning, particularly construction for greater energy efficiency and for an aging population.
\end{abstract}

JEL Codes: A12, J11, J13, J14, O13, Q01, Q56

Keywords: demography, urbanization, ageing, population growth, universal education, contraception, reproductive health, urban planning, sustainability, hunger, fertility decline

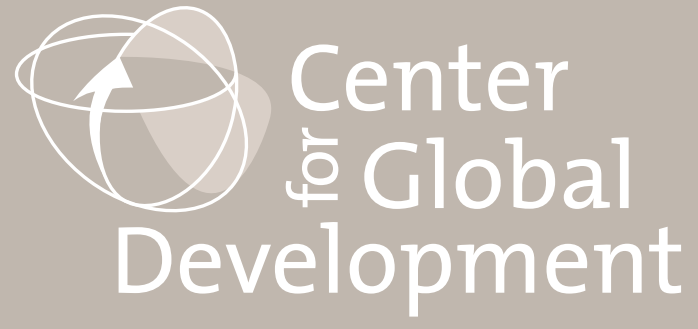

$$
\begin{aligned}
& \text { Working Paper } 220 \\
& \text { July } 2010
\end{aligned}
$$




\title{
Beyond Population: Everyone Counts in Development
}

\author{
Joel E. Cohen \\ Abby Rockefeller Mauzé Professor \\ Laboratory of Populations \\ Copyright @ 2010 by Joel E. Cohen
}

I am grateful for the helpful comments of Richard P. Cincotta, Rachel Nugent, Samuel Preston, Barbara H. Seligman, and Duncan Thomas, the assistance of Priscilla K. Rogerson, the hospitality of the family of William T Golden in New York and Michael Hochberg at the University of Montpellier II during my work on this chapter, and the financial support of U.S. National Science Foundation grant DMS-0443803.

CGD is grateful for contributions from the the William and Flora Hewlett Foundation in support of this work.

Joel E. Cohen. 2010. "Beyond Population: Everyone Counts in Development." CGD Working Paper 220. Washington, D.C.: Center for Global Development. http://www. cgdev.org/content/publications/detail/1424318

Center for Global Development 1800 Massachusetts Ave., NW Washington, DC 20036

202.416.4000

(f) 202.416 .4050
The Center for Global Development is an independent, nonprofit policy research organization dedicated to reducing global poverty and inequality and to making globalization work for the poor. The views expressed in this paper are those of the author and should not be attributed to the board of directors or funders of the Center for Global Development. 


\section{Foreword}

Demographic changes are slow and often slip by unnoticed until they are well underway, but their course can be altered by concerted policy efforts. In this paper, produced under the auspices of the Center for Global Development's Demographics and Development Initiative, Joel Cohen highlights contemporary demographic trends and discusses their implications for development policy. In doing so, he demonstrates how smart policies can change the future course of the size, structure, and distribution of populations.

Demographic changes in the 21 st century are different from those of the 20th century. As Cohen points out, old people now outnumber young people, urban people outnumber rural people, population growth is dramatically slower across the globe except in Africa, and most of the world lives in developing countries, by a ratio of six to one by the year 2050 .

The policy implications of these trends are profound. A growing dominance of older people changes the epidemiological profile of a country and the causes of mortality. To deal with graying populations, countries will need to make accommodations in health care, infrastructure, and public finances. Other economic and social effects are possible, and governments should begin to plan how to ameliorate the negative consequences, such as drawdowns in savings, and benefit from the positive, such as healthier old age. 
Cohen points to similarly positive implications of the urbanization underway in all developing countries—such as lower per-capita energy use — but also raises questions about how well urban populations will be able to sustainably meet their needs. He recommends urgent attention to several priorities: primary and secondary education enrollment, with particular focus on preparation for civil engagement; unmet need for contraception among the 200 million still lacking access; and urban planning and management that is cognizant of resource scarcity and aging populations.

The Demographics and Development Initiative is generously supported by a grant from the William and Flora Hewlett Foundation. Recognizing that fertility, mortality, and migration are fundamental forces that shape (and are shaped by) the prospects for economic and social development, CGD seeks through this initiative to bring policy-oriented analyses of demographic phenomena into the debates about development-friendly policies.

Rachel Nugent

Deputy Director, Global Health

Center for Global Development 


\section{Introduction}

The aim of this essay is to review some of the most important demographic trends between 2010 and 2050, to indicate some of their implications for economic and global development, and to suggest some possible policies in response to these trends and implications.

Section 2 insists that the interactions of population, economics, the environment, and culture cannot be neglected. This theme is developed by examples throughout the chapter. Section 3, looking backward, reviews the remarkable transitions of global population in this decade and this century. Section 4 , looking forward, identifies four major trends in global human population over the coming half century. Section 5 considers future sustainability and widespread hunger now.

Turning to the consequences for action of the demographic trends previously reviewed, the concluding section 6 reviews three broad classes of panaceas, then proposes policy options in three areas: universal primary and secondary education, including education for global and household civility; contraceptive and reproductive health services; and age-sensitive urban planning, including more energy efficient buildings. Some important, complex areas of policy are not discussed in section 6: international migration, with all its economic, political, moral and social implications; pro-natalist family policy, in countries with present or incipient declines in population; policies regarding HIV/AIDS, tuberculosis, malaria, influenza, and other major infectious diseases; and policies regarding the balance between preventive public health and curative medicine, in particular, regarding tobacco, the major preventable cause of death in the world. $^{12}$ 


\section{Population, economics, the environment and culture all matter}

A key challenge is to keep demographic variables in sight while keeping them in perspective. Population matters, but not to the exclusion of economics, the environment and culture. To keep all four of these concerns in mind, I envision a tetrahedron with "population" at the peak and "economics," "environment," and "culture" at the three corners of the triangular base (Figure 1). This visual image is a reminder that "population," "economics," "the environment," and "culture" (including law, politics, education, religion, institutions and traditions) are constantly interacting partial descriptions of the human situation. Depending on the viewer's orientation, the peak could just as well be occupied by economics, the environment, or culture as by population, provided that the interactions of all four are kept in mind. 
Figure 1. Global change is driven by the interaction of population, the environment, economics, and culture (including politics, law and education).

\section{population}

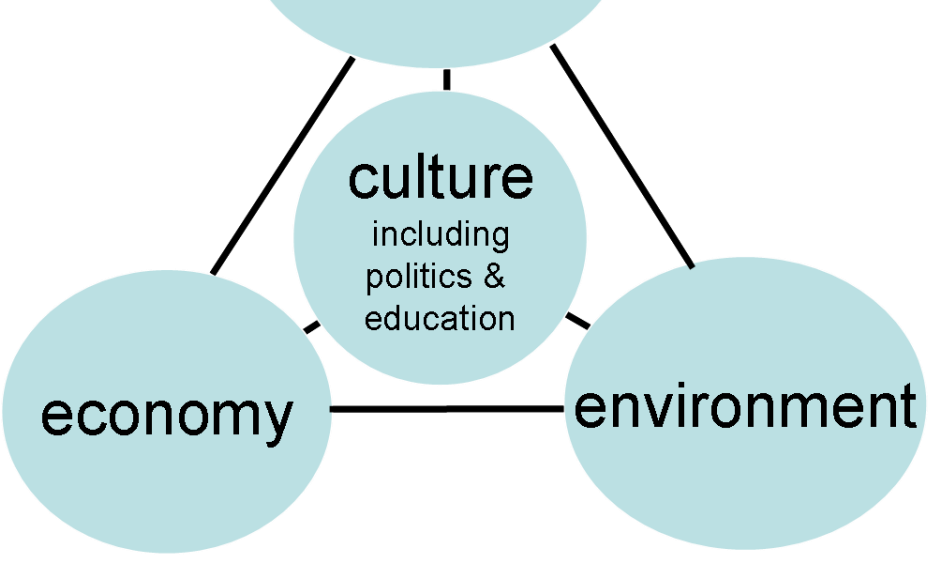

\section{Population in transition}

The global human population has undergone remarkable transitions in this decade and this century.

\subsection{Transitions of this decade}

The current decade spans three unique, important transitions in the history of humankind. ${ }^{3}$ Before 2000, young people always outnumbered old people. From 2000 forward, old people will outnumber young people. Until approximately 2007, rural people always outnumbered urban people. From 2008 forward, urban people will outnumber rural people. From 2003 on, the median woman worldwide (though not the average woman) had, and will probably continue to have, too few or just enough children during her lifetime to replace herself and the father in the following generation. ${ }^{4}$ Because very high fertility continues in some regions, and because high fertility in recent decades has led to a high proportion now of young women of an 
age to bear children, the average woman worldwide has roughly half a child more than required to replace herself and the father in the following generation.

\subsection{Transitions of this century}

The century with 2000 as its midpoint marks three additional unique, important transitions in human history. First, no person who died before 1930 had lived through a doubling of the human population. No person born in 2050 or later is likely to live through a doubling of the human population. In contrast, everyone born in 1965 or earlier and still alive saw human numbers more than double from 3.3 billion in 1965 to 6.8 billion in 2009 .

The peak global population growth rate ever reached, about $2.0 \%$ or $2.1 \%$ a year, corresponding to a doubling time of 33-35 years, occurred between 1965 and 1970, ${ }^{5,6}$ as the less developed countries reached their peak growth rate of $2.48 \%$ a year, corresponding to a doubling time of 28 years. This peak was driven in large part by China and India. China reached its all time peak annual population growth rate of $2.61 \%$ per year, corresponding to a doubling time of 27 years, in 1965-70. India reached its all time peak annual population growth rate of $2.3 \%$ per year, corresponding to a doubling time of 30 years, in 1975-80. Other countries with smaller populations reached peak growth rates at other times, with smaller global demographic effects. ${ }^{7}$

Global human population never grew with such speed before the 20th century and is likely never again to grow with such speed. Our descendants will look back on the late 1960s peak as the most significant demographic event in the history of the human population even though those of us who lived through it did not recognize it at the time.

Second, the dramatic fall since 1970 of the global population growth rate to $1.1 \%$ or $1.2 \%$ a year in $2009^{8}$ resulted primarily from choices by billions of couples around the world to limit 
the number of children born. Never before the 20th century was a fall in the global population growth rate voluntary.

Third, the last half century saw, and the next half century will see, an enormous shift in the demographic balance between the more developed regions of the world and the less developed ones. In 1950 the less developed regions had roughly twice the population of the more developed ones. By 2050 the ratio will probably exceed six to one. ${ }^{9}$ These colossal changes in the composition and dynamics of the human population by and large escape public notice.

\section{Four big demographic trends to 2050}

Four major trends are expected to dominate changes in the human population in the coming half-century, according to most demographers. The population will grow bigger, more slowly, more urban, and older than in the 20th century.

Less certain than these trends, though potentially no less important, are future possible trends in international and internal (within-country) migration and in the structure of families and households. Unfortunately, present demographic data and tools provide inadequate quantitative guidance about future changes in these factors. I will mention migration and household structure later.

It is important to approach all such projections with modesty. These projections remain uncertain because, for example, no one knows how closely future rates of birth, death and urbanization will resemble their assumed future trends. No one knows precisely how confident to be about these projections. Despite their uncertainty, the projections do suggest some challenges humanity will face over the next 50 years. There is little disagreement among demographers 
about the main lines to these projections, though research and debate continue about refinements of calculation, reliability, and public presentation.

\subsection{The global human population is still growing rapidly, but not in all places equally}

Although the rate of population growth has fallen since the 1970s, current rates (as a percentage) and absolute numbers of global population growth are still greater than any experienced prior to World War II. Rapid global population growth has not ended. ${ }^{10}$ Human numbers currently increase by 75 million to 80 million people annually, the equivalent of adding another U.S. population every four years or so. ${ }^{11}$ Whereas the first absolute increase in population by one billion people took from the beginning of time until the early 19th century, one billion people will be added to today's population in only 13 to 14 years. The world's population is projected to reach over 9 billion by 2050, depending on future birth and death rates. ${ }^{12}$ The anticipated increase from 2009 to 2050 exceeds the total population of the world in 1930, which was around 2 billion.

Childbearing choices made today and tomorrow will help determine the future size of the human population. A difference in fertility of a single child per woman's lifetime between now and 2050 alters the projection for 2050 by 3 billion, a difference equal to the entire world population in 1960 (Figure 2). 
Figure 2. Global population history since 1950 and alternative projections to 2050 , according to the United Nations Population Division (2006 Revision). In the unlikely event that fertility does not decline at all from today's levels (black diamonds), population would grow to 11.9 billion by 2050, nearly doubling the 6 billion people alive in 1999. The medium projection of 9.2 billion people (blue squares) assumes that family planning will be more widely practiced and the trend towards smaller families will continue. If, compared to this assumption, women have on average one more child for every two women (red squares), world population could reach $\mathbf{1 0 . 8}$ billion by 2050 . If women have on average one fewer child for every two women (green triangles), world population could be 7.8 billion by 2050 . $^{1}$

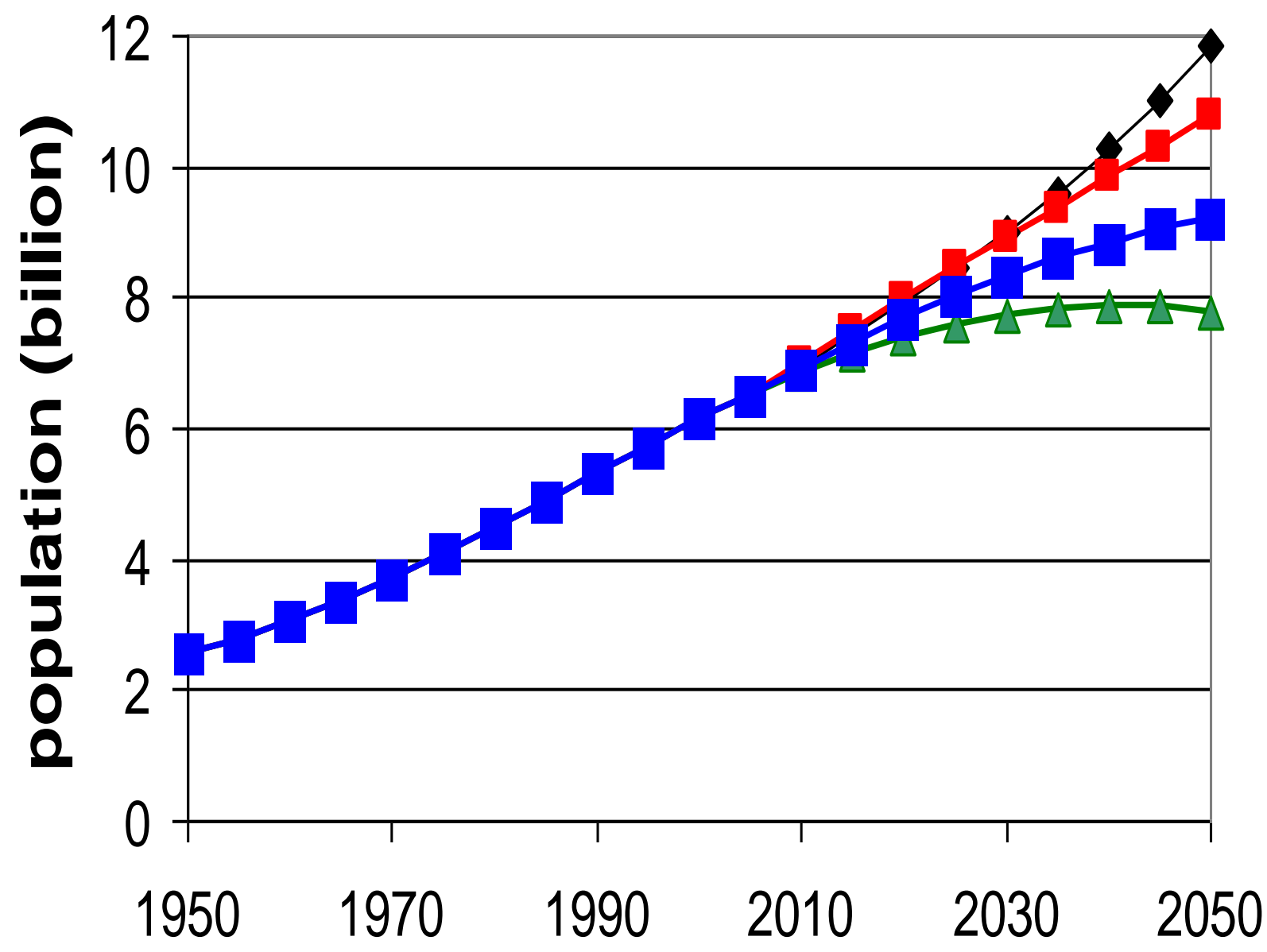


Virtually all population growth in the next 40 years is expected to happen in today's economically less developed regions. Between 2005 and 2050 population will at least triple in Afghanistan, Burkina Faso, Burundi, Chad, Congo, Democratic Republic of the Congo, East Timor, Guinea-Bissau, Liberia, Mali, Niger and Uganda. ${ }^{13}$ These countries are among the poorest on Earth. Despite higher death rates at every age, poor countries' populations grow faster than rich countries' populations because birth rates in poor countries are much higher. At present fertility rates, the average woman would bear 2.8 children in her lifetime in the poor countries and 1.6 children in a lifetime in the rich countries. ${ }^{14}$

Half the global increase will be accounted for by just nine nations. Listed in order of their anticipated contribution, they are India, Pakistan, Nigeria, Democratic Republic of the Congo, Bangladesh, Uganda, the U.S., Ethiopia and China. ${ }^{15}$

In contrast, 51 countries or areas, most of them economically more developed, will lose population between now and 2050. Germany is expected to drop from 83 million to 79 million people, Italy from 58 million to 51 million, Japan from 128 million to 112 million and, most dramatically, the Russian Federation from 143 million to 112 million. Thereafter Russia will be slightly smaller in population than Japan. ${ }^{16}$

Of current global population growth, 75-80 million a year, 5\% occurs in developed countries, $95 \%$ in developing countries. By 2050 , the rich countries will lose a million persons a year, while the developing nations will add 35 million a year. So the annual global increase will have dropped by more than half -- from roughly 79 million to roughly 34 million -- by 2050 . Only in the low projection of the United Nations will global population growth have ended by 2050. In the 2007 revision of the probabilistic population projections of the International Institute 
for Applied Systems Analysis, the median population projection peaks around nine billion people near $2070 .^{17}$

The imbalances between the rapid population growth of poor countries and the slowing population growth or decline in population size of rich countries will increase the potential for international migration. The extent of future international migration will depend on economics (e.g. the demand for workers in rich countries and the opportunities for employment in developing countries), culture (e.g. the desire and ability of receiving countries to accommodate and assimilate immigrants) and the environment. ${ }^{18}$ Migration has little immediate effect on global population size but may accelerate the slowing of population growth. Migrants who move from high-fertility to low-fertility regions or from rural to urban areas, or the descendants of those migrants, often adopt the lower-fertility patterns of their new home with some time delay.

From 2005 to 2050 , the more developed regions are projected to have about 2.2 million more immigrants than emigrants a year. The U.S. is expected to receive about half of these. ${ }^{19}$ If recent levels of international migration continue, the 98 million net migrants expected to move to the more developed regions during 2005-2050 would more than offset the projected loss of 73 million people in those countries from an excess of deaths over births. ${ }^{20}$ These projections have even greater uncertainty than the projections of births and deaths because, more than most demographic variables, future international migration is subject to intentional policy choices by national governments. Those choices are difficult to predict.

\subsection{Population will grow more slowly, but not in all places equally}

During the decades after World War II, before implementation of China's one-child policy, couples in the poor countries realized that their children were surviving better than in 
previous decades. In the late 1960s, couples started lowering their fertility. The world's population growth rate fell from around $2.1 \%$ per year in $1965-70$ to about $1.1 \%$ per year in 2009, roughly by half in 40 years. That extraordinary achievement was the result primarily not of coercion, but of widespread education and widespread adoption of voluntary modern family planning.

If fertility continues to fall as anticipated, people will have fewer siblings, cousins, aunts, and uncles. Extended families will shrink. Reproduction and child rearing will occupy a smaller portion of adult life, diminishing the importance of the reproductive function of marriage. Unless patterns of co-habitation change in ways contrary to long-term historical trends (Figure 3), the average number of people per household will continue to decline and the numbers of households will rise even faster than the numbers of people. 
Figure 3. Distribution of living arrangements among white persons aged 65 years or over in the United States of America, 1850-1990. Source: Ruggles (2001) ${ }^{21}$

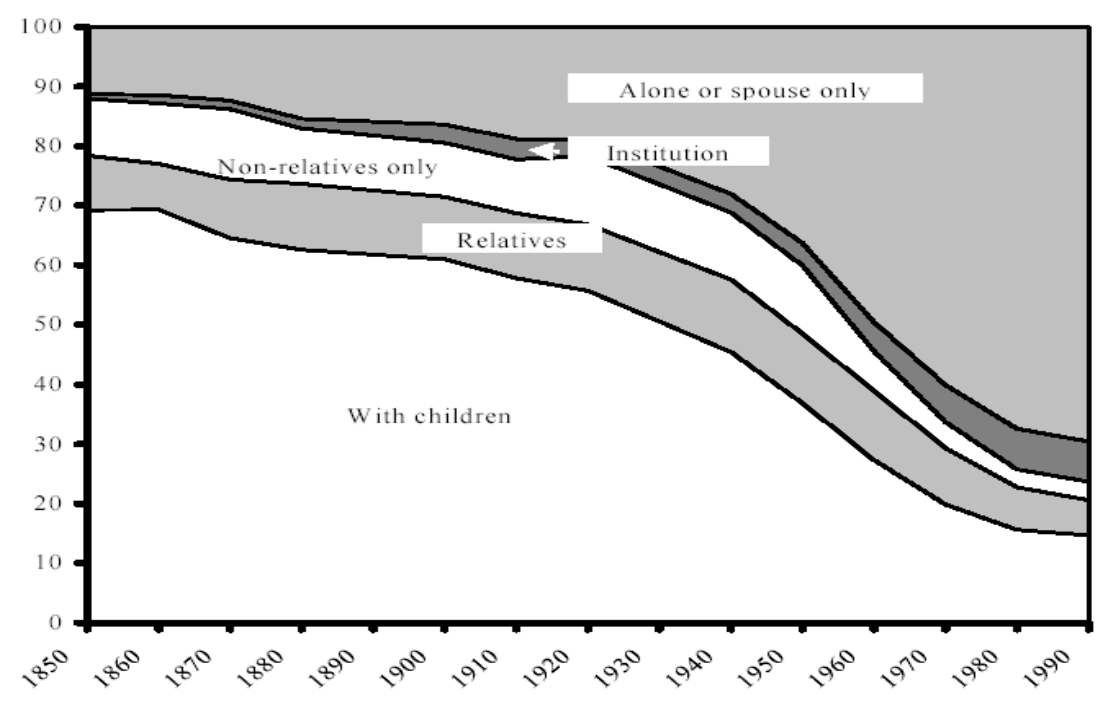

Changing household demography will have environmental consequences because important energy demands are more closely associated with numbers of households than with numbers of people. ${ }^{22,23,24}$ For example, Mackellar and colleagues ${ }^{22}$ (p. 860, their Table 7) analyzed energy consumption from 1970 to 1990 separately for the more developed regions and the less developed regions according to two models, one based on numbers of individuals and the other based on numbers of households. For the more developed regions, the growth of population (individuals) accounted for $18 \%$ of the growth of energy consumption, while changes in income and technology accounted for $36 \%$ of the growth of energy consumption. In the alternative analysis, the growth in the number of households in the more developed regions accounted for $41 \%$ of the growth of energy consumption, while changes in income and technology accounted for $13 \%$. In the less developed regions over this interval, the alternative analyses differed only slightly because household sizes changed little. 
The differences between projections of the future based on numbers of individuals and projections based on numbers of households were striking. When Mackellar and colleagues ${ }^{22}$ ( $\mathrm{p}$. 862, their Table 9) assumed constant emissions of carbon dioxide per person between 1990 and 2100 , total emissions of carbon dioxide were projected to increase by $88 \%$; but when they assumed constant emissions of carbon dioxide per household, total carbon dioxide emissions were projected to increase by $167 \%$ between 1990 and 2100 . The contrasts were equally striking when Mackellar and colleagues assumed constant rates of increase in emissions per person or per household. Even if these projections may not be definitive in quantitative detail, they made an unmistakable point: changes in fertility and other behaviors that influence the sizes and numbers of future households could affect future impacts of humans on their environment at least as much as, and possibly much more than, changes in total population size.

\subsection{Population will grow older, but not in all places equally}

Slowing population growth everywhere means that the 20th century was probably the last in human history in which younger people outnumbered older ones. The proportion of all people who were children aged four years and younger peaked in 1955 at $14.5 \%$ and gradually declined to $9.5 \%$ by 2005 , whereas the fraction of people aged 60 years and older increased from a low of $8.1 \%$ in 1960 to $10.4 \%$ in $2005 .^{25}$ Around 2000 each age-group constituted about $10 \%$ of humanity. Now and henceforth the elderly have the numerical upper hand.

This crossover in the proportions of young and old reflected both improved survival and reduced fertility. The average life span grew from perhaps 30 years at the beginning of the 20th century to more than 65 years at the beginning of the 21 st century. ${ }^{26}$ The increase in average lifespan resulted partly from increasing incomes and partly from increases in length of life at a 
given level of income. But reduced fertility influenced the proportions of young and old more than increasing longevity influenced those proportions because reduced fertility added smaller numbers to the younger age groups.

The demographic transition from high birth and death rates (with high variability over time in both birth rates and death rates) to low birth and death rates (low death rates especially at early ages) with lower variability in both birth and death rates was accompanied by an epidemiologic transition. As the age structure of a population shifted from young to old, the fraction of deaths caused primarily by infectious diseases and diseases associated with childbirth declined while the fraction of deaths caused primarily by non-communicable diseases increased. ${ }^{27}$ The original statements of the theory of the epidemiological transition made assumptions about the directions of causation between change in the overall level of mortality and change in the distribution of causes of death which have been criticized subsequently. ${ }^{28}$ Among the causal factors to be sorted out are changes in age structure; changes in behavioral factors including personal hygiene, addictions to alcohol and tobacco, and the handling (e.g. pasteurization) of food; improvements in the availability of food; and changes in institutions that govern the distribution of food in crises and the delivery of public health measures, including those affecting water purification and delivery, sewage removal, immunization, and other medical technologies. Notwithstanding the considerable uncertainty about what caused what, a worldwide shift has occurred in the causes of death. As a proportion, fewer people die from infections and more people die from heart diseases, stroke, metabolic diseases such as diabetes, and cancers. The epidemiologic transition has advanced further in the more developed countries than in the less developed countries, but in countries at a given level of life expectancy the patterns in the causes of death seem broadly similar. 
This global graying seems likely to require major changes in personal and national systems of health care and in public and private health expenditures. The rising costs of treating diseases which can be prevented or postponed by behavioral and environmental choices (such as some cardiovascular disease, some kinds of diabetes, some cancers, some psychological disorders, and several addictions) seem likely to affect the organization and financing of public health and medical care in coming decades.

The graying of the population is not proceeding uniformly around the globe. In 2050 nearly one person in three will be 60 years or older in the more developed regions and one person in five in the less developed regions. Because the less developed regions are starting with smaller numbers of elderly people, the increases in the numbers and the proportions of elderly will be much more dramatic in the less developed zones than in the more developed regions. For example, between 2005 and 2050, the number of people aged $60+$ has been projected ${ }^{29}$ to increase by $60 \%$ and the number of people aged $80+$ has been projected to increase $160 \%$ in the more developed regions, while the corresponding increases for these same two age groups in the less developed regions were projected at $270 \%$ and $560 \%$, respectively. Thus aging will proceed even more rapidly in emerging markets than in the more developed regions. But for now the higher present proportions of elderly in more developed countries have excited the interests of some economists in the opportunities for pension funds of rich (older) countries to invest in the more rapid growth of poor (younger) countries. ${ }^{30}$

By contrast with the elderly populations of most of the more developed countries, in 11 of the least developed countries_-Afghanistan, Angola, Burundi, Chad, Democratic Republic of the Congo, Equatorial Guinea, Guinea-Bissau, Liberia, Mali, Niger and Uganda- - half the population will still be aged 23 years or younger in $2050 .^{31}$ 
Some analysts of national security have suggested that "population aging and population decline in the developed world will constrain the ability of the United States and its traditional allies to maintain national and global security. ... " ${ }^{, 32}$ They argued that the effects of population ageing and decline will be felt through changes in demographic size, economic performance, and social mood. "The growth rates of the service-age population, of the working-age population, and (therefore) of the GDP in the typical developed country will all fall far beneath their historical trend and also beneath growth rates in most of the rest of the world. In many developed countries, ... GDPs may stagnate or even decline.” Economically, "As populations age and economic growth slows, employees may become less adaptable and mobile, innovation and entrepreneurship may decline, rates of savings and investment may fall, public-sector deficits may rise, and current account balances may turn negative." Finally, "Psychologically, older societies will become more conservative in outlook and possibly more risk-averse in electoral and leadership behavior. Elder domination of electorates will tend to lock in current public spending commitments at the expense of new priorities. Smaller family size may make the public less willing to risk scarce youth in war. Meanwhile, the rapid growth in minority populations, due to ongoing immigration and higher-than-average minority fertility, may undermine civic cohesion and foster a new diaspora politics. ${ }^{, 33}$

The effects they projected were not purely negative. "In the developing world, ... some developing countries will learn to translate the 'demographic dividend' created by their declining fertility into higher savings rates, greater human capital development, efficient and open markets, rising incomes and living standards, and stable democratic institutions. Some will follow the meteoric success path of a South Korea or Taiwan, others the slower-but-still-steady success path of an India or Malaysia." ${ }^{34}$ 
This perspective gives insufficient attention to the good news about population aging. ${ }^{35}$ One aspect of that good news is offered by a T-shirt that says: "50 is the new 30. " The agespecific disability rate at age 60 is defined as the fraction of 60 -year-olds who are unable to do the normal activities of daily living, like getting out of bed, getting dressed, washing, and feeding oneself. The United States' disability rate has been falling about $1.5 \%$ per year for the last 25 years. The fraction of people aged 60 who are fit is much higher than in the past. A similar improvement in the functioning of older people is going on in Japan and elsewhere. A higher level of education when a person is young predicts a lower risk of disability when the person is older, and education predicts better than income whether an individual will develop a chronic condition such as diabetes or functional limitations. ${ }^{36}$ However, it is not yet clear whether the reductions in disability rates result from improvements in the environment and assistive devices that permit greater independence at any given level of health or from improvements in health. ${ }^{37}$

Additional good news about population aging is the suggestion that "a country's chances for meaningful democracy increase as its population ages. ${ }^{, 38}$ Richard Cincotta tracked the ratio of the number of young adults (individuals aged 15 to 29 ) to the working age population (individuals aged 15 to 64 ) in countries with at least half a million people and compared that proportion of young adults to the Freedom House's rating of the country as "free" starting in the middle 1970s. The lower the proportion of young adults, the older the population's age structure. "When the young-adult proportion dropped into the range between 36 and 42 percent, full democracies evolved without the political backsliding or military coups that had been so common in Asian and Latin American politics. Where high levels of democracy emerged well before the young-adult proportion declined, countries typically settled into less liberal regimes-as did Ecuador, Fiji, Malaysia, Pakistan, and Venezuela." A country reached a 50-50 chance of 
being considered "free" when the young-adult proportion fell to 39\%. If this criterion holds in the future, the likelihood of the appearance of a stable democracy seems to be highest in two regions, along Africa's Mediterranean coast (Morocco, Algeria, Tunisia, Libya, and Egypt), "none of which has experienced democracy in the recent past," and in South America (Ecuador, Colombia, and Venezuela), "each of which attained liberal democracy demographically 'early' but was unable to sustain it." Cincotta pointed out that, according to the statistical pattern he identified, China, Cuba, and Russia should be liberalizing democracies, and Thailand should have kept its democracy but did not. Thus demography is not destiny politically, but it seems to matter considerably. ${ }^{39}$

Age structure also affects energy use. In the United States in the 1980s and 1990s, the older the age of householders, the lower the energy use per person for transportation and the higher the residential energy use per person. ${ }^{40}$ The share of household expenditures for energy appears higher for older householders also in China and India. ${ }^{41}$ If these patterns are general and if they persist in the future, future increases in the elderly proportion of the population could substantially increase energy consumption per person and the proportion of energy in household expenditures. While the decline in fertility lowers the rate of population growth, reducing pressure on the environment, the increased proportions of elderly and the high propensity among the elderly to head households has the contrary effect of increasing demands on the environment. ${ }^{22}$ (pp. 860-861) Demography is not destiny environmentally either, but it seems to matter considerably.

There is little historical precedent for societies as elderly as many of those anticipated for 2050. Consequently, it is difficult to justify empirically any precise image of how such a society will work or feel to its participants. Nevertheless, economics, the environment, and culture will 
continue to offer choices about how to influence the quality of a future aged society. For example, the labor force participation of the elderly will be influenced by conventional ages at retirement, by whether jobs for the elderly can gradually taper from fulltime employment to part time employment, and by whether the tasks in elderly employment can be tailored to accommodate the strengths and weaknesses of the elderly. The psychological and physical health of the elderly and their families will be influenced by whether the elderly can maintain stable life partners through marriage or otherwise and by the creativity and adaptability of institutions that employ and care for the elderly. The environment, human-built and natural, will play a crucial role in providing easy money management and telephoning, nearby shopping and public transportation, doors that are easy to open with arthritic hands, protection from infectious diseases, and access to nature. Culture will influence how the elderly are enabled to connect with the young, to continue to grow emotionally and intellectually, and to value themselves even if they are not making as much or any money. Foresightful policies that affect all these possibilities can greatly influence the future world of the elderly.

\subsection{Population will become more urban, but not in all places equally}

People are concentrated in cities. Just over half of all people live in cities on less than $3 \%$ of the land area. Among the city dwellers in 2005, approximately $51 \%$ lived in cities with fewer than half a million people. The less densely settled half of the land has about $2 \%$ of the world's people. Half of Earth's land is very thinly settled.

The world's cities will face an unprecedented confluence of a rapidly aging population and rapid growth in total numbers of people if recent trends continue as projected to $2050 .{ }^{42}$ Virtually all of the world's population growth will be in urban areas, and the world's rural 
population will be declining by 2050 . In effect, the poor countries will have to build the equivalent of a city to accommodate one million people every five days or so for the next 40 to 45 years. $^{43}$ This growth in the number of urban people is driven partly by the excess of births over deaths in cities, partly by the migration of rural people into cities, and partly by the reclassification of settlements which have grown enough to move from the category of rural to the category of urban. ${ }^{44}$

Figure 4. Urban and rural populations, by development group, $1950-2050 .^{42}$ The vertical solid line marks 2019, when the less developed regions are projected to have equal urban and rural populations and the world's rural population will begin to decline from its all time peak.

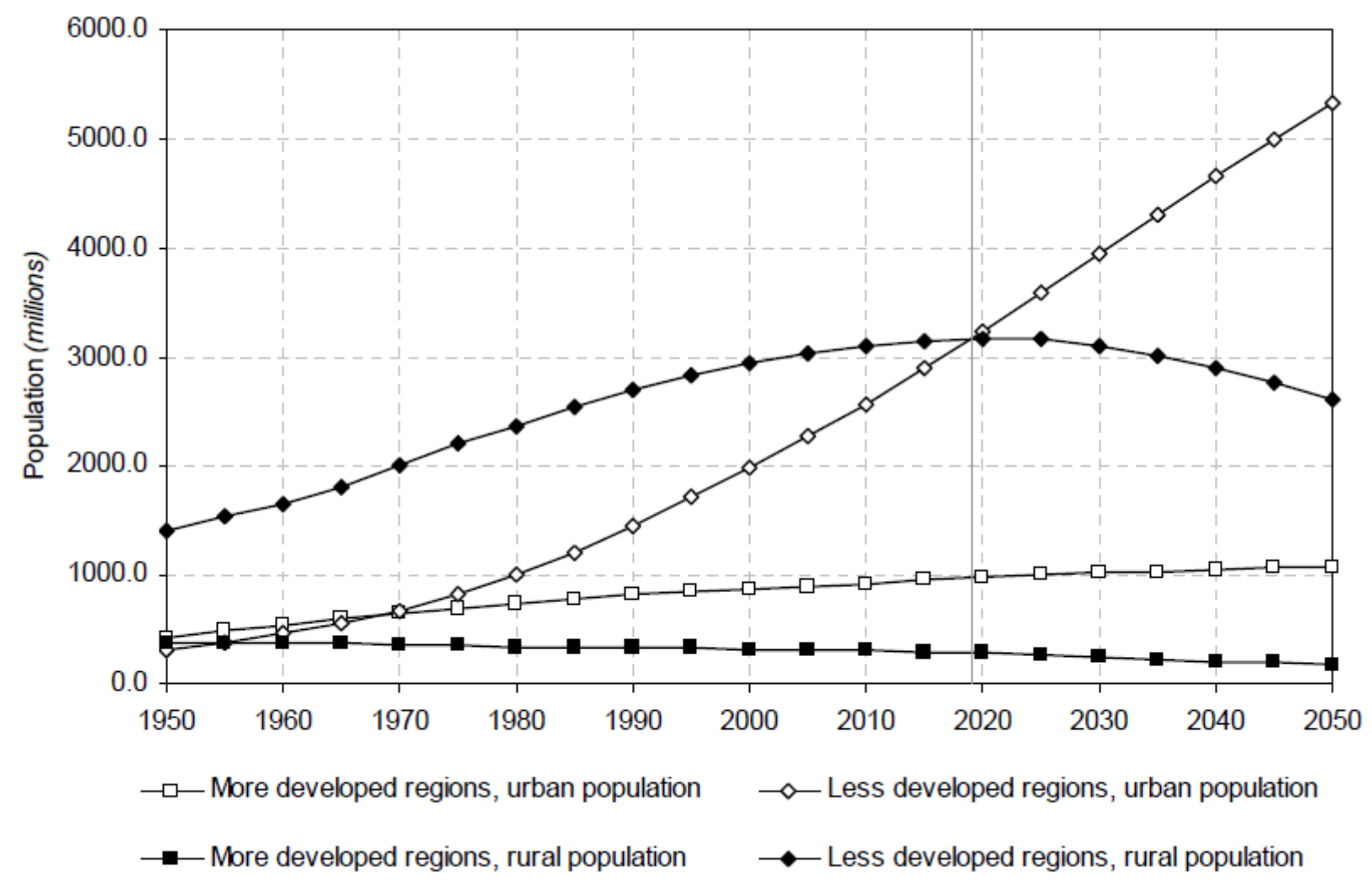


The United Nations urbanization projections have been criticized as yielding a "systematic overestimation of the world urbanization." ${ }^{45}$ Instead of considering urban-rural fertility differentials explicitly, the projections extrapolate differences in the observed rates of growth of urban and rural populations within each country. These growth rates compound natural increase, migration, and reclassification. Unfortunately, there are no widely accepted alternative projections. These projections should be accepted, like all projections, skeptically.

The rapid growth of cities may have environmental advantages and disadvantages. For example, in a very densely settled city like New York, where many people use public transportation, the average person was reported to produce $71 \%$ less carbon-dioxide-equivalent greenhouse gases than the United States average (7.1 metric tons per year versus 24.5$).{ }^{46}$ Exactly what these numbers included was unclear. Did they include only the emissions within the city, or emissions from the production of all energy directly consumed within the city even if the energy (e.g., electricity) was generated elsewhere, or did they include the emissions generated elsewhere to produce and transport to the city goods and services other than energy? Were the comparative numbers computed consistently? The large definitional uncertainty of demographic statistics on urban populations also applies to greenhouse gas emissions statistics, especially those for urban or other localized regions.

The growth of cities is expected to be a serious threat to endemic species around them. ${ }^{47}$ The environment may respond with a threat to cities. Of the roughly 20 megacities with more than 10 million people in 2005 , the 15 on coasts or coastal rivers could be adversely affected by even modest rises in sea level. ${ }^{48}$ 


\section{Sustainability in the future, hunger now}

Projections of billions more people in the cities of the developing countries and more elderly people everywhere, coupled with hopes of economic growth especially for the world's poor, raise concerns in some quarters about the sustainability of present and future populations.

The number of undernourished people rose by 75 million in 2007, bringing the estimated world total to 923 million undernourished people, roughly one person in seven. ${ }^{49}$ In the year before June 19, 2009, according to the United Nations Food and Agriculture Organization, roughly another hundred million people fell below the hunger threshold of 1800 kilocalories per day, bringing the total number of the world's hungry people to more than one billion. ${ }^{50}$

This prodigious stain of human hunger results from collective human choices, not biophysical necessities. While hundreds of millions hungered, farmers grew enough to feed $50 \%$ more people than are alive now, at least at a subsistence level. The estimated cereal production in the 2007-2008 crop year exceeded 2.1 billion metric tons of cereal grains, ${ }^{51}$ sufficient to feed more than 10 billion people an adequate vegetarian diet. But as demographer-sociologist Kingsley Davis observed in 1991, "There is no country in the world in which people are satisfied

with having barely enough to eat. ${ }^{, 52}$ While too many people eat too much, ${ }^{53}{ }^{54}$ more than a billion eat less than barely enough.

The question of sustainability, or of human carrying capacity, is not a question about mere survival, but whether 2050's billions of people can live with freedom of choice and material prosperity, however freedom and prosperity may then be defined, and whether their children and their children's offspring will be able to continue to live with freedom and prosperity, however they may define them in the future. 
A crucial ingredient is equity in the distribution of wealth. As of 2000 , the richest $1 \%$ of adults owned $40 \%$ of global assets, compared on an exchange rate basis (not purchasing power parity). ${ }^{55}$ The next $1 \%$ of adults owned $11 \%$ of global assets. Thus the top $2 \%$ of adults owned $51 \%$ of global assets. The inequality in wide distribution of wealth would have been even greater had children been included, as children are concentrated in poor families and poor countries. Why are inequitable distributions of income and wealth a significant part of the challenge of sustainability? When some people have vastly greater incomes and/or assets than others, the poor may value highly, as crucial to survival, resources that the wealthy value very little because they have so many alternatives. The exhaustion, pollution, or extinction of those resources may scarcely affect the wealthy while bringing disaster or death to the poor.

Worry about sustainability is as old as recorded history. Cuneiform tablets from 1600 B.C. showed that the Babylonians feared the world was already too full of people. In 1798 Thomas Malthus renewed these concerns, ${ }^{56}$ as did Donella Meadows and her co-authors in their 1972 book The Limits to Growth ${ }^{57}$ While some people have fretted about too many people, optimists have offered reassurance that deities or technology will provide for humankind's wellbeing.

Attempts to quantify Earth's human carrying capacity or a sustainable human population size face the challenge of understanding nature's constraints, human choices and the interactions between them. ${ }^{58}$ For example, what will humans desire and accept as the average level and distribution of material well-being in 2050 and beyond? What technologies will be used? What domestic and international political institutions will be used to resolve conflicts? What economic arrangements will provide credit, regulate trade, set standards and fund investments? What social and demographic arrangements will influence birth, health, education, marriage, migration and 
death? What physical, chemical and biological environments will people want to live in? What level of variability will people accept? (If people do not mind seeing human population size drop by billions when the climate becomes unfavorable, they may regard a much larger population as sustainable when the climate is favorable.) What level of risk are people willing to live with? (Are mud slides, hurricanes or floods acceptable risks or not? The answer will influence the area of land viewed as habitable.) What time horizon is assumed? What will people's values and tastes be in the future? As anthropologist Donald L. Hardesty noted in 1977, "A plot of land may have a low carrying capacity, not because of low soil fertility but because it is sacred or inhabited by ghosts. ${ }^{\circ 9}$

Most published estimates of Earth's human carrying capacity uncritically assumed answers to one or more of these questions. ${ }^{60}$ My book How Many People Can the Earth Support? analyzed more than five dozen of these estimates published from 1679 onward. Estimates made in the past half a century ranged from less than one billion to more than 1,000 billion. I learned that these estimates are political numbers, intended to persuade people either that too many humans are already on Earth or that there is no problem with continuing rapid population growth. By contrast, scientific numbers are intended to describe reality. Because no estimates of human carrying capacity have explicitly addressed the questions raised above, taking into account the diversity of views about their answers in different societies and cultures at different times, no scientific estimates of sustainable human population size can be said to exist.

No one knows the path to sustainability because no one knows the destination, if there is one. Too often, attention to long-term sustainability is a diversion from the immediate problems of making tomorrow better than today, a task that offers much room for science and constructive 
action. As economist Robert Cassen remarked, "Virtually everything that needs doing from a population point of view needs doing anyway." ${ }^{, 61}$

\section{Policy choices}

The strategies usually proposed by policy advocates in response to world problems of poverty, inequity, disease, exploitation, violence, and environmental transformation, are of three main kinds: ${ }^{58}$ create a bigger pie (amplify human productive capacity through investments in technology, and sometimes also through investments in education and health), use fewer forks (increase access to reproductive health care and contraception to slow population growth voluntarily), and practice better manners (improve people's interactions by reforming institutions, policies and practices to achieve greater social and legal equity).

More concrete policy options can be tied to the demographic trends described above. These options are: universal primary and secondary education, including education for global and household civility; eliminating unmet needs for contraception and reproductive health; and demographically sensitive urban planning, including construction for greater energy efficiency. Before turning to these possibilities, I want to examine critically a recommendation for a larger population as a solution to poverty.

\subsection{Collier's Bottom Billion}

Seeking to find the most effective ways for the world's poorest to escape poverty, the distinguished Oxford University economist Paul Collier identified 980 million people in 2006 living in what he and others called a "poverty trap." ${ }^{.62}$ The 58 countries where these "bottom billion" lived were poorer in 2000 than they had been in $1970 .{ }^{63}$ These countries included 
Angola, Central African Republic, Haiti, Liberia, Sudan, Somalia and Zimbabwe. Collier defined a state as failing if a rating of twenty aspects of governance and policy fell below a cutoff for a continuous period of four years. More than three quarters of the bottom billion lived in countries that were, at some time, failing states. Collier defined a turnaround as a subjectively rated large improvement over any time interval that was sustained for at least five years. Collier "estimated the probability of a turnaround, year by year, among all the potential turnaround countries and searched among a wide range of potential characteristics for those that mattered. ... [O]nly three characteristics ... were reliably significant [in a statistical model] in determining whether a turnaround occurred. Starting from being a failing state, a country was more likely to achieve a sustained turnaround the larger its population, the greater the proportion of its population that had secondary education, and - perhaps more surprisingly - if it had recently emerged from civil war."64

Collier did not recommend that a failing state have a civil war to emerge from, perhaps because he also found that any particular incipient reform was less likely to progress if the country had recently emerged from civil war. ${ }^{65}$ But Collier did recommend having a large population. Especially in the poorest countries, his call for a large population seems no less perverse than would have been a call for a recent civil war.

Collier wrote, "Having a large population and having a high proportion of people with secondary education both help. They may well be pointing to the same thing: countries need a critical mass of educated people in order to work out and implement a reform strategy."66 Yet the secondary completion rate in these failed states (where it has been measured) is so low that the population size hardly limits the number of people with a secondary education. In Haiti, for example, in 2000, the fractions of people with completed lower secondary education to an 
uncompleted first level of tertiary education were 30\% among those aged 15-19 and 31\% among those aged 30-34 ${ }^{67}$ In the Central African Republic, the corresponding fractions were $20 \%$ and $24 \%$. These countries could triple or quintuple their numbers of high school graduates without any increases in population. Further, a country could probably achieve most economies of scale that might result from having a larger population within its borders through collaboration or exchange with its neighbors. The absolute numbers of people are less a constraint on a country's escape from poverty than the way the existing people are educated and organized into countries. Collier's analysis neglected the adverse effects of rapid population growth on a country's ability to provide education of high quality for its young.

Collier's analysis also measured inappropriately the adverse effects of rapid population growth on a country's age structure. Collier apparently considered among his independent variables the fraction of young people 15-to-24 years old, divided by total population, according to Richard P. Cincotta [personal communication, 26 March 2009]. Collier found this fraction not to be a statistically significant predictor of a turnaround. As Cincotta pointed out, Collier's choice of the total population as the denominator, rather than the working age population aged 15-64 years, rendered indistinguishable (by his measure) the countries with extremely young populations (high proportions aged 0-14) and the countries with high proportions of older people. Cincotta suggested, and I agree, that Collier's analysis might have revealed the adverse consequences of rapid population growth and a youthful distribution of the working-age population had he included an independent variable like numbers of individuals 15 -to-24 or 15to-29 divided by numbers of individuals $15+$ or 15 -to-64. It would be highly desirable to have independent scholars try to replicate Collier's results using his and other related predictors. ${ }^{39}$ 


\subsection{Universal primary and secondary education}

Universal primary and secondary education could substantially influence whether the human population heads for 7.8 billion or for 10.8 billion in $2050 .{ }^{68,69}$ In many developing countries, women who completed secondary school averaged at least one child fewer per lifetime than women who completed primary school only (Figure 5), though the direction of causation may not have been only from education to fertility and other factors besides education surely affected fertility as well. ${ }^{70}$

Figure 5. In many countries at early stages of economic development, women who complete secondary school average at least one child fewer per lifetime than women who complete primary school only, as measured by the total fertility rate. The absolute levels of fertility vary widely from country to country. Murphy and Carr (2007), as redrawn. ${ }^{68}$

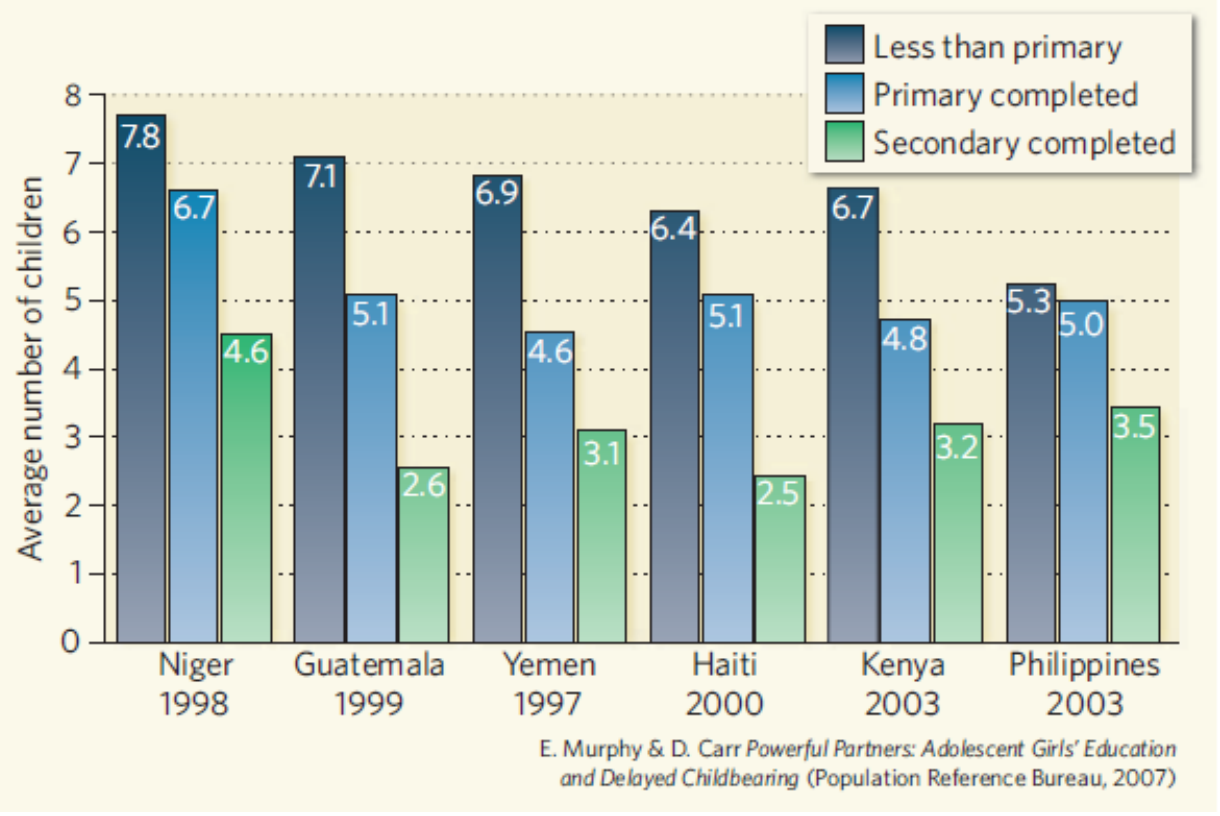


In Niger in 1998, for example, women who completed secondary education had 31\% fewer children (on average, 4.6 per lifetime) than those who completed only primary education (6.7), as measured by the total fertility rate. In Yemen in 1997, women who completed primary school had 4.6 children on average whereas women who completed secondary school had 3.1 children on average. Different societies have different thresholds for reaping education's benefits of reduced fertility and lower population growth. In some sub-Saharan African societies, lifetime fertility was reduced only among girls who had had 10 or more years of schooling. ${ }^{71}$

It is promising that fertility decisions are influenced not just by a woman's own education level, but also by that of the reproductive-age women around her. In one study, for clusters of 25 women of reproductive age in 22 countries of sub-Saharan Africa, higher average levels of education for the women around a given individual reduced her birth rate, independent of urbanization and her individual education level. ${ }^{72}$ Education of the surrounding community reduced the total fertility rate only when the average length of education reached four or more years, so minimum thresholds of education were required to reap the fertility benefits of an educated social milieu. The community's level of education contributed to improved survival of children in addition to influencing fertility. ${ }^{73}$

Recent data on age-specific educational attainment and economic growth in 101 countries during 1970-2000, analyzed in a simple regression model, indicated "consistently positive, statistically significant education effects on economic growth for some age and education groups ... The current [Millennium Development Goals]'s focus on universal primary education is important but insufficient. It needs to be complemented with the goal of giving broad segments of the population at least a completed junior secondary education. Only this is likely to give 
initially poor countries the human capital boost that is necessary to bring large segments of the population out of poverty. For more industrialized countries, tertiary education of younger adults also is an important determinant of economic growth." 74 Wolfgang Lutz and colleagues concluded that "better education does not only lead to higher individual income but also is a necessary (although not always sufficient) precondition for long-term economic growth." Giving a broad segment of the population a secondary education benefits parents, children, economies, and societies through reduced fertility, improved childhood survival, and better possibilities for economic growth.

As an added bonus, the probability of obesity decreases broadly linearly with increasing years of full-time education where the relation has been studied (Australia, Canada, England and Korea), and the reduction is greater for women than for men. ${ }^{75}$ Causality apparently runs from education to obesity because the reduced educational opportunities of obese children hardly affect the relationship.

In addition to how many years children are in school, the content of education also matters. What should education teach? Two subjects of primary and secondary education deserve particular attention if education is to enhance development: first, what Fernando Reimers ${ }^{76}$ has called education for global civility and, second, what I would call education for household civility.

Reimers argued that schools should teach students to tolerate and appreciate individual and cultural diversity on a global scale, and to settle conflicts through peaceful negotiation. For Reimers, “[g]lobal civility ... is largely about understanding, solidarity, and empathy with others. ${ }^{, 77}$ Reimers contrasted global civility with three other contenders to be the principal goal of education: economic competitiveness, nationalism, and local (religious, cultural, or political) 
relevance. A number of international commentators on the goals of basic and secondary education agreed that global civility ought to displace these three powerful competitors as the principal goal of education. ${ }^{78}$ For a world made smaller by the addition of several billion more people, the increasing concentration of people in cities, economic globalization, ever more widespread technologies for cultural contacts, and the constraints of a physically finite Earth, the primacy of global civility as a crucial subject for education at every level seems compelling.

Education should also teach civility within the household. Skills are required to resolve competing demands and desires in ways that protect individual interests and preserve the benefits of having a household, especially when resources are limited. Concretely, if a household's dominant male gets some money or meat, he should be educated to consider the needs for education and protein (and other resources) of the women and children in the house. If a household's dominant female has to discipline children, she should be educated to do it in a way that preserves their dignity, health, autonomy and sense of fairness. When spouses or domestic partners of a household have to resolve conflicts between them, education should give them the skills to hear and respect the concerns of the other and to preserve, if at all possible, the integrity and beneficial aspects of the household.

The stakes involved in educating young people for household civility reach far beyond the household in an aging world. Spouses or domestic partners are each other's primary caregivers in old age. A society that invests wisely in teaching its young people to cope with the normal stresses of living with a partner over the long term will reap a rich return in reduced needs to institutionalize a rapidly growing number of elderly people. ${ }^{79}$ The individuals themselves will, of course, benefit even more. 
The additional costs of universal primary and secondary education, beyond what is already being spent, have been estimated and are affordable. ${ }^{80}$

\subsection{Contraceptive and reproductive health services}

A woman is considered to have an unmet need for contraception "if she is fecund, sexually active and not using any contraceptive method, and does not want a child for at least two years. If a woman is pregnant or amenorrheic after giving birth, she is considered to have an unmet need if she had not wanted the pregnancy or birth either when it occurred or ever." ${ }^{81}$ In 2008, some 215 million women were considered to have an unmet need for contraception by modern, effective means, 75 million pregnancies were unintended, and about 20 million women

had unsafe abortions. ${ }^{82}$ Providing modern contraception to women who need it and maternal and newborn health services would reduce unintended pregnancies to an estimated 22 million per year and unsafe abortions to perhaps 5.5 million per year (assuming abortion laws remained unchanged), as well as offering numerous other health, social, and economic benefits. Meeting the unmet need for modern contraception in developing countries would cost an estimated \$3.6 billion in 2008 U.S. dollars, on top of the $\$ 3.1$ billion being spent to serve those who are currently using modern methods.

In addition to eliminating the unmet need for contraception globally, it would be highly desirable to support more research to improve the safety, efficacy, cultural acceptability, and gender generality of contraceptive methods. The present palette of contraceptive choices is far from ideal. Research achievements in this area could benefit both developed and developing countries and the costs should be shared between them. 
Education and contraceptive and reproductive health services share a highly desirable moral quality: where such services are available, the potential customers seek them for their own value.

\subsection{Urban planning, including more energy efficient buildings}

As mentioned above, the poor countries will have to build the equivalent of a city to accommodate one million people every five days for the next 40 to 45 years. ${ }^{43}$ The world's urban infrastructure in 2000 supported roughly half the number of people it will have to support in 2050. The challenge of meeting such immense needs is obvious. The opportunities are less obvious but equally immense. Cities can be planned to accommodate a higher proportion of elderly people than they have ever accommodated before (bus stops and subway stops with chairs for waiting; doors that open with push bars or electronically rather than with round door knobs that are difficult to grasp). Neighborhoods can be planned to accommodate local needs for shopping, banking, social life, entertainment, and greenery. New cities can be located away from rising seas and away from lands of prime agricultural productivity or of unique biological diversity. Cities can be planned with transport networks that take advantage of population density to make central medical, educational, cultural, and business facilities easily accessible at low energetic cost.

The cost of energy will have to pervade thinking not only about a large scale structure of neighborhoods and transportation networks, but also the design of buildings for housing and business. According to UN-Habitat, ${ }^{83}$ "much of the current urban building stock in Europe was designed and constructed when energy was cheap and global warming was unheard of.” In the U.K., buildings account for about $45 \%$ of all energy consumption, and homes for $27 \%{ }^{84}$ In the 
U.K., $70 \%$ of the buildings in 2050 will be buildings that exist today; therefore, in addition to building more energy-efficient new buildings, it is also imperative to improve the energyefficiency of existing buildings. ${ }^{85}$ The largest single use of energy in buildings is for space heating, often consuming as much energy as water heating, lighting, cooling and all other purposes put together. As shown above, elderly individuals spend a higher proportion of their household budgets on energy, and the proportion of elderly people in the population is virtually certain to rise. These behavioral and demographic trends underline the importance of assuring that the domestic and non-domestic buildings of futures cities are designed to be efficient in every use of energy, especially space heating. Improved energy efficiency of buildings would have both economic and environmental benefits.

Acknowledgments. I am grateful for the helpful comments of Richard P. Cincotta, Rachel Nugent, Samuel Preston, Barbara H. Seligman, and Duncan Thomas, the assistance of Priscilla K. Rogerson, the hospitality of the family of William T Golden in New York and Michael Hochberg at the University of Montpellier II during my work on this chapter, and the financial support of U.S. National Science Foundation grant DMS-0443803.

JOEL E. COHEN is Abby Rockefeller Mauzé Professor of Populations and head of the Laboratory of Populations at the Rockefeller University and Columbia University. Author or coauthor of 14 books and more than 360 chapters or papers, he won the Tyler Prize for Environmental Achievement, the Nordberg Prize for excellence in writing in the population sciences, and the Fred L. Soper Prize of the Pan American Health Organization for his work on Chagas' disease. Portions of this article originally appeared in Joel E. Cohen, "Human 
population grows up," Scientific American September 2005. These portions are Copyright ( 2005 Scientific American. Some portions appeared revised in a book edited by Laurie Mazur entitled A Pivotal Moment: Human Population, the Environmental Crisis, and the Justice Solution (Island Press, 2009). 
${ }^{1}$ World Health Organization, WHO Report on the Global Tobacco Epidemic, 2008: The MPOWER Package. Geneva, WHO. http://www.who.int/tobacco/mpower/gtcr_download/en/index.html

${ }^{2}$ WHO estimated in 2008 that tobacco killed 100 million people in the 20th century and could kill as many as 1 billion in the 21 st century.

${ }^{3}$ Cohen, Joel E. Human population grows up. Scientific American Sept. 2005.

${ }^{4}$ Wilson, Chris and Pison, Gilles La majorité de l'humanité vit dans un pays où la fécondité est basse. Population et Sociétés No. 405, Oct. 2004. ISSN 01847783.

${ }^{5}$ United Nations, Department of Economic and Social Affairs, Population Division, World Population Prospects: The 2006 Revision and World Urbanization Prospects, http://esa.un.org/unpp

${ }^{6}$ This means that if the growth rate of $2.1 \%$ per year were constant, the population would double in 33 years. This doubling time is not a prediction that the population will double in 33 years, any more than a speedometer reading of 60 miles an hour is a prediction that a car will be exactly 60 miles from its present location after one hour. In fact, because of a fall in population growth rates after 1970, it took an estimated 39 years for the population of the world to double from 3 billion in 1960 to 6 billion in 1999 .

${ }^{7}$ Saudi Arabia's population growth rate reached $5.85 \%$ per year in $1980-85$, corresponding to a doubling time of less than 12 years.

${ }^{8}$ UN Population Division http://esa.un.org/unpp

${ }^{9}$ UN Population Division http://esa.un.org/unpp

${ }^{10}$ For example, according to CIA estimates, the highest national population growth rate in 2009 was $3.69 \%$ per year in the United Arab Emirates, corresponding to a doubling time of less than 19 years. Extraordinarily rapid population growth persists in some countries, despite the decline in the global average.

${ }^{11}$ United Nations, Department of Economic and Social Affairs, Population Division, World Population Prospects: The 2006 Revision, Highlights, Working Paper No. ESA/P/WP.202, 2007.

${ }_{12}^{12}$ UN Population Division http://esa.un.org/unpp

${ }^{13}$ UN Population Division http://esa.un.org/unpp

${ }_{15}^{14}$ UN Population Division http://esa.un.org/unpp

${ }^{15}$ UN Population Division http://esa.un.org/unpp. The U.S. appears in this list because of its large population size, high rates of immigration, and higher fertility among the immigrant population compared to the native population. These factors give the U.S. a higher overall fertility rate than that of most other more developed countries.

${ }^{16}$ UN Population Division http://esa.un.org/unpp

${ }^{17}$ Wolfgang Lutz, Warren Sanderson, Sergei Scherbov, 2008. The coming acceleration of global population ageing. Nature 451, 716-719 (7 February 2008), doi:10.1038/nature06516. http://www.iiasa.ac.at/Research/POP/proj07/

${ }^{18}$ For example, rising sea levels could drive massive investments in protective infrastructure, increasing the numbers of jobs, or could profoundly disrupt economies, decreasing the numbers of jobs.

${ }^{19}$ United Nations, Department of Economic and Social Affairs, Population Division, International Migration 2006, http://www.un.org/esa/population/publications/2006Migration_Chart/Migration2006.pdf

${ }^{20} \mathrm{Ibid}$.

${ }^{21}$ Ruggles, Steven (2001). Living arrangements and well-being of older persons in the past. Population Bulletin of the United Nations: Living Arrangements of Older Persons. Special Issue, Nos. 42/43 (2001), pp. 111-161. United Nations Sales No. E.01.XIII.16.

${ }^{22}$ MacKellar, F. L., Lutz, W., Prinz, C. \& Goujon, A. Population, households, and CO2 emissions. Pop. Dev. Rev. 21, 849-865 (1995).

${ }^{23}$ O'Neill, Brian C. and Chen, Belinda S. 2002 Demographic determinants of household energy use in the United States. Population and Development Review 28 (Supplement, Population and Environment: Methods of Analysis): 53-88. Stable URL: http://www.jstor.org/stable/3115268

${ }^{24}$ Keilman, Nico 2003 The threat of small households. Nature 421:489-490, 30 January.

${ }^{25}$ UN Population Division http://esa.un.org/unpp

${ }^{26}$ UN Population Division http://esa.un.org/unpp

${ }^{27}$ Abdel R. Omran, 1971. The epidemiologic transition. Milbank Memorial Fund Quarterly 49(4):509-538; Omran AR. Epidemiologic transition. In: Ross JA, ed., International Encyclopedia of Population. London, The Free Press, 1982: 172-183.

${ }^{28}$ John C. Caldwell, 2001. Population health in transition. Bulletin of the World Health Organization 79 (2):159160 . 
${ }^{29}$ United Nations Population Division, 2004 World Population Prospects, from /esa.un.org/unpp 3 March 2006

${ }^{30}$ Bernhard Fischer, Helmut Reisen, 1995. "Pension Fund Investment from Ageing to Emerging Markets," OECD Development Centre Policy Briefs 9, OECD, Development Centre.

Helmut Reisen, 2000. Pensions, Savings and Capital Flows: From Ageing to Emerging Markets. Edward Elgar

Publishing, Incorporated ISBN-13: 9781840643084

${ }^{31}$ UN Population Division http://esa.un.org/unpp

${ }^{32}$ Jackson, Richard, Howe, Neil, Strauss, Rebecca and Nakashima, Keisuke 2008 The Graying of the Great Powers: Demography and Geopolitics in the 21st Century. Center for Strategic \& International Studies (CSIS), Washington, DC. May 2008. http://www.csis.org/component/option,com_csis_pubs/task,view/id,4453/. Major Findings of the Report, page 2.

${ }^{33}$ Ibid., p. 6.

${ }^{34}$ Ibid., p. 6.

${ }^{35}$ Vaupel, James W. 2010 Biodemography of human ageing. Nature 464:536-542, 25 March.

${ }^{36}$ Lavery, Diana and Lee, Marlene 2009 Effects of early life on elderly health. Population Reference Bureau, Today's Research on Aging, No. 16, pp. 1-5, April.

${ }^{37}$ Spillman, Brenda C., Changes in elderly disability rates and the implications for health care utilization and cost. Milbank Quarterly 82(1):157-194, March 2004.

${ }^{38}$ Cincotta, Richard P. 2008 How democracies grow up: Countries with too many young people may not have a fighting chance at freedom. Foreign Policy pp. 80-82, March/April.

${ }^{39}$ Large population size and high population density do not appear to contribute substantially to the risk of internal violent conflicts, according to recent empirical studies. Urdal, Henrik 2008 Demographic aspects of climate change, environmental degradation and armed conflict. United Nations Expert Group Meeting on Population Distribution, Urbanization, Internal Migration and Development. Population Division, Department of Economic and Social Affairs, United Nations Secretariat, New York, 21-23 January 2008. UN/POP/EGM-URB/2008/18. 16 January 2008. 25 pp.

${ }^{40}$ O'Neill, Brian C. and Chen, Belinda S. 2002 Demographic determinants of household energy use in the United States. Population and Development Review 28(Supplement, Population and Environment: Methods of Analysis): 53-88. Stable URL: http://www.jstor.org/stable/3115268

${ }^{41}$ Pachauri, Shonali, and Leiwen Jiang. 2008. The household energy transition in India and China. Energy Policy 36:4022-4035. doi:10.1016/j.enpol.2008.06.016.

${ }^{42}$ United Nations Population Division 2008 World Urbanization Prospects: The 2007 Revision. ST/ESA/SER.A/237. Department of Economic and Social Affairs. United Nations, New York. ESA/P/WP/205

${ }^{43}$ Cohen, Joel E. Sustainable cities. Bulletin of the American Academy of Arts and Sciences 61(4):6-8, summer 2008.

${ }^{44}$ Unfortunately, these categories are differently and somewhat arbitrarily defined in different countries, and therefore fuzzy on the global scale.

${ }^{45}$ Bocquier, Philippe 2005 World Urbanization Prospects: an alternative to the UN model of projection compatible with the mobility transition theory. Demographic Research 12(9):195-236, May 4. www.demographic-research.org ${ }^{46}$ City of New York, plaNYC: A Greener, Greater New York City. Office of the Mayor, City of New York, 2007, p. 9.

${ }^{47}$ Robert I. Mcdonald, Peter Kareiva, Richard T.T. Forman, The implications of current and future urbanization for global protected areas and biodiversity conservation. Biological Conservation 141 (2008) 1695-1703.

${ }^{48}$ The fifteen coastal megacities are Tokyo, New York-Newark, Mumbai, Shanghai, Kolkata, Buenos Aires, Dhaka, Jakarta, Los Angeles-Long Beach-Santa Ana, Karachi, Rio de Janeiro, Osaka-Kobe, Cairo, Lagos, Manila. The exceptional inland megacities are México City, São Paulo, Delhi, Beijing, and Moscow.

${ }^{49}$ Food and Agricultural Organization, Food Outlook \& Global Market Analysis, Nov. 2008, p. 1. http://www.fao.org/docrep/011/ai474e/ai474e00.HTM

${ }^{50}$ Associated Press, World Hunger Reaches the 1 Billion People Mark. New York Times June 19, 2009. Filed at 8:19 a.m. ET.

${ }^{51}$ Food and Agricultural Organization, Food Outlook \& Global Market Analysis, Nov. 2008, if p. 2.

${ }^{52}$ Davis, Kingsley, and Mikhail S. Bernstam, eds., Resources, environment and population: Present knowledge and future options, Supplement to vol. 16 of Population and Development Review, 1990. New York: Population Council, New York: Oxford University Press, 1991. 
53 "About two-thirds of adults in the United States are overweight, and almost one-third are obese, according to data from the National Health and Nutrition Examination Survey (NHANES) 2001 to 2004."

http://www.win.niddk.nih.gov/STATISTICS/, accessed 20090701.

${ }^{54}$ Franco Sassi, Marion Devaux, Michele Cecchini and Elena Rusticelli, The obesity epidemic: analysis of past and projected future trends in selected OECD countries. OECD Health Working Papers 45,

DELSA/HEA/WD/HWP(2009)3. Organisation for Economic Co-operation and Development 20-Mar-2009.

http://www.olis.oecd.org/olis/2009doc.nsf/linkto/delsa-hea-wd-hwp(2009)3

55 James Davies, Susanna Sandström, Anthony Shorrocks and Edward Wolff, World Distribution of Household

Wealth. World Institute for Development Economics Research of the United Nations University. 5 December 2006, Foreign Press Association, London; United Nations Secretariat, New York.

${ }^{56}$ Malthus, T.R., An Essay on the Principle of Population ... Complete 1st ed. (1798) and partial 7th ed. (1872) reprinted in On Population, Gertrude Himmelfarb, ed. Modern Library, New York, 1960.

${ }^{57}$ Meadows, Donella H., Meadows, Dennis L., Randers, Jírgen and Behrens III, William W., The Limits to Growth: A Report for the Club of Rome's Project on the Predicament of Mankind. Signet, New American Library, New York, 1972 1st ed.; 1974 2nd ed.

${ }^{58}$ Cohen, Joel E., How Many People Can the Earth Support? New York: W. W. Norton, 1995.

${ }^{59}$ Hardesty, Donald L., Ecological Anthropology New York: John Wiley, 1977.

${ }^{60}$ Jeroen C. J. M. Van Den Bergh and Piet Rietveld, 2004 Reconsidering the limits to world population: metaanalysis and meta-prediction. BioScience 54(3):195-204, March.

${ }^{61}$ Cassen, Robert et al., Population and Development: Old Debates, New Conclusions. Transaction Publishers, New Brunswick, NJ, Oxford, UK, 1994.

${ }^{62}$ Collier, Paul 2007 The Bottom Billion: Why the Poorest Countries are Failing and What Can Be Done About It. Oxford University Press, Oxford, New York.

${ }^{63}$ Ibid. p. 9.

${ }^{64}$ Ibid. p. 70.

${ }^{65}$ Ibid. p. 72.

${ }^{66}$ Ibid. p. 71.

${ }^{67}$ W Lutz, A Goujon, S K.C., W Sanderson. 2007. Reconstruction of population by age, sex and level of educational attainment of 120 countries for 1970-2000. Vienna Yearbook of Population Research, vol. 2007, pp 193-235. Data downloaded 2009-03-02 from http://www.iiasa.ac.at/Research/POP/edu07/index.html

${ }^{68}$ Cohen, Joel E. Make secondary education universal. Nature 456:572-573, December 4.

${ }^{69}$ Lutz, Wolfgang. 2009b. Editorial: Towards a world of 2-6 billion well-educated and therefore healthy and wealthy people. Journal of the Royal Statistical Society A 172.4:701-705.

${ }^{70}$ Population Reference Bureau Women's Education and Family Size in Selected Countries, 1990s (2008). Available at www.prb.org/Educators/TeachersGuides/ HumanPopulation/Women.aspx, based on Demographic and Health Surveys, 1991-1999.

${ }^{71}$ Jejeebhoy, S. J. Women's Education, Autonomy, and Reproductive Behaviour: Experience from Developing Countries (Clarendon Press, 1995).

${ }^{72}$ Kravdal, Øystein 2002 Education and fertility in Sub-Saharan Africa: individual and community effects. Demography 39(2):233-250, May. Stable URL: http://links.jstor.org/sici?sici=0070$3370 \% 28200205 \% 2939 \% 3 \mathrm{~A} 2 \% 3 \mathrm{C} 233 \% 3 \mathrm{AEAFISA} \% 3 \mathrm{E} 2.0 . \mathrm{CO} \% 3 \mathrm{~B} 2-\mathrm{K}$

${ }^{73}$ Kravdal, Øystein 2004 Child mortality in India: The community-level effect of education. Population Studies 58(2):177-192. DOI: 10.1080/0032472042000213721

${ }^{74}$ Lutz, Wolfgang, Cuaresma, Jesus Crespo and Sanderson, Warren 2008 The demography of educational attainment and economic growth. Science 319:1047-1048 (plus Technical Appendix, pp. 1-11), 22 February.

${ }^{75}$ Franco Sassi, Marion Devaux, Jody Church, Michele Cecchini, Francesca Borgonovi, Education and obesity in four OECD countries, OECD Health Working Papers No. 46, DELSA/HEA/WD/HWP(2009)4 Organisation for Economic Co-operation and Development 15-Jun-2009 http://www.olis.oecd.org/olis/2009doc.nsf/linkto/delsa-heawd-hwp(2009)4

${ }^{76}$ Fernando Reimers, "Educating for Global Competency", Chapter 14 in . E. Cohen, Martin Malin, eds. 2009 International Perspectives on the Goals of Universal Basic and Secondary Education. Routledge, New York, London. Isbn: 978-0-415-99766-9.

${ }^{77}$ Reimers, p. 193. 
${ }^{78}$ J. E. Cohen, Martin Malin, eds. 2009 International Perspectives on the Goals of Universal Basic and Secondary Education. Routledge, New York, London. Isbn: 978-0-415-99766-9

${ }^{79}$ United Nations Population Division, Living Arrangements of Older Persons Around the World. New York, 2005. ST/ESA/SER.A/240.

${ }^{80}$ Cohen, Joel E., Bloom, David E. 2005 Cultivating Minds. Finance and Development 42(2):8-14, June. International Monetary Fund, Washington, DC.

Paul Glewwe, Meng Zhao, and Melissa Binder, 2006. Achieving Universal and Basic Secondary Education: How Much Will It Cost? Working paper of the Project on Universal Basic and Secondary Education, American Academy of Arts and Sciences. http://www.amacad.org/publications/Glwwe.pdf

Cohen, J. E., Bloom, David E. and Malin, Martin, eds. 2006 Educating All Children: A Global Agenda. 616 pp. MIT Press, Cambridge, MA. http://mitpress.mit.edu/026253293X

${ }^{81}$ John A. Ross and William L. Winfrey, Unmet need for contraception in the developing world and the former Soviet Union: an updated estimate. International Family Planning Perspectives, 2002, 28(3):138-143. This is the standard definition used in the Demographic and Health Survey series.

${ }^{82}$ Singh, Susheela, Darroch, Jacqueline E., Ashford, Lori S. and Vlassoff, Michael 2009 Adding It Up: The Costs and Benefits of Investing in Family Planning and Maternal and Newborn Health. Guttmacher Institute and United Nations Population Fund, New York. ISBN: 978-1-934387-04-7. P. 4.

${ }^{83}$ UN-Habitat. 2008. State of the World's Cities 2008/2009: Harmonious Cities. United Nations Human Settlements Programme (UN-Habitat). London and Sterling, Va.: Earthscan. 259 pp. P. 164.

${ }^{84}$ Kelly, M. J. 2010. Energy efficiency, resilience to future climates and long-term sustainability: the role of the built environment. Phil. Trans. R. Soc. A 368:1083-1089. doi: 10.1098/rsta.2009.0212.

${ }^{85}$ Kelly, M. J. 2009. Retrofitting the existing UK building stock. Building Research and Information 37.2:196-200, Mar/Apr. doi: 10.1080/09613210802645924. 